\title{
Relationship Between Reproduction Traits and Functional Longevity in Canadian Dairy Cattle
}

\author{
A. Sewalem, ${ }^{*} \dagger^{1}$ F. Miglior, ${ }^{\star} \dagger$ G. J. Kistemaker, $\dagger$ P. Sullivan, $\dagger$ and B. J. Van Doormaal $\dagger$ \\ *Agriculture and Agri-Food Canada, Dairy and Swine Research and Development Centre, Sherbrooke, Quebec, J1M 1Z3 Canada \\ †Canadian Dairy Network, Guelph, Ontario, N1K 1E5 Canada
}

\begin{abstract}
The aim of this study was to use survival analysis to assess the relationship between reproduction traits and functional longevity of Canadian dairy cattle. Data consisted of 1,702,857; 67,470; and 33,190 Holstein, Ayrshire, and Jersey cows, respectively. Functional longevity was defined as the number of days from first calving to culling, death, or censoring; adjusted for the effect of milk yield. The reproduction traits included calving traits (calving ease, calf size, and calf survival) and female fertility traits (number of services, days from calving to first service, days from first service to conception, and days open). The statistical model was a Weibull proportional hazards model and included the fixed effects of stage of lactation, season of production, the annual change in herd size, and type of milk recording supervision, age at first calving, effects of milk, fat, and protein yields calculated as within herd-year-parity deviations for each reproduction trait. Herd-year-season of calving and sire were included as random effects. Analysis was performed separately for each reproductive trait. Significant associations between reproduction traits and longevity were observed in all breeds. Increased risk of culling was observed for cows that required hard pull, calved small calves, or dead calves. Moreover, cows that require more services per conception, a longer interval between first service to conception, an interval between calving to first service greater than $90 \mathrm{~d}$, and increased days open were at greater risk of being culled.
\end{abstract}

Key words: functional longevity, reproduction trait, female fertility, calving performance

\section{INTRODUCTION}

Longevity is a highly desirable trait that considerably affects overall profitability in the dairy industry. With

Received March 8, 2007.

Accepted December 17, 2007.

${ }^{1}$ Corresponding author: sewalem@cdn.ca increased longevity, the mean production of the herd increases for 2 reasons. First, a greater proportion of the culling decisions are based on production. Second, the proportion of mature cows, which produce more milk than young cows, is increased (Allaire and Gibson, 1992; VanRaden and Wiggans, 1995). Longevity is determined by voluntary and involuntary culling decisions of individual farmers. In the process of making decisions on culling, the farmers or producers will take into account production, health, fertility, and other functional traits such as milking speed, milking temperament, and calving ease. Generally, culling because of poor production is called voluntary culling, and culling for reasons other than poor production is called involuntary culling. Reducing the rate of involuntary culling allows a higher voluntary replacement rate, which can increase profits for a dairy farm.

Reproductive performance is another major factor affecting profitability of a dairy herd. Inadequate herd reproductive performance, manifested as prolonged calving intervals, increased involuntary culling, or both, can result in less milk and fewer calves per cow per year. Other consequences include more involuntary culling and, therefore, increased replacement costs and, ultimately, lower net returns. Until 10 to $15 \mathrm{yr}$ ago, most national dairy cattle research and breeding programs were mainly oriented toward yield traits (Leitch, 1994). However, functional traits, such as reproduction, longevity, and health traits, are of increased interest to producers to improve herd profitability. Miglior et al. (2005), in their comparison of international selection indices, reported that selection indices have evolved worldwide, shifting their focus from primarily production to a more balanced breeding approach that includes longevity, udder health, conformation, and reproduction. In February 2008, a new genetic evaluation system for reproductive performance will be available to Canadian dairy farmers. The newly developed system is based on a 16-trait animal model that includes all available female fertility and calving traits collected by DHI (Jamrozik et al., 2005; Miglior et al., 2007). The availability of these traits provides an opportunity for more 
Table 1. Percentage of records for calving traits ${ }^{1}$ in each class for Holstein (HO), Ayrshire (AY), and Jersey (JE)

\begin{tabular}{|c|c|c|c|c|c|c|c|c|c|c|c|}
\hline \multicolumn{4}{|c|}{$\mathrm{CE}$} & \multicolumn{4}{|c|}{$\mathrm{CZ}$} & \multicolumn{4}{|c|}{ CS } \\
\hline & $\mathrm{HO}$ & $\mathrm{AY}$ & $\mathrm{JE}$ & & $\mathrm{HO}$ & $\mathrm{AY}$ & JE & & $\mathrm{HO}$ & $\mathrm{AY}$ & JE \\
\hline Unassisted & 60.33 & 72.05 & 86.97 & Small & 9.16 & 10.23 & 10.31 & Dead & 5.88 & 4.69 & 5.25 \\
\hline Easy pull & 32.82 & 24.27 & 12.62 & Medium & 64.17 & 63.66 & 65.74 & Alive & 94.12 & 95.31 & 94.75 \\
\hline Hard pull & 6.61 & 3.52 & 0.35 & Large & 26.67 & 26.11 & 23.95 & & & & \\
\hline Surgery & 0.24 & 0.16 & 0.06 & & & & & & & & \\
\hline
\end{tabular}

${ }^{1} \mathrm{CE}$ = calving ease, $\mathrm{CZ}=$ calf size, $\mathrm{CS}=$ calf survival.

detailed studies about the relationship of reproduction traits with other traits of economic importance.

Several reports have indicated that poor reproductive performance, manifested as prolonged calving intervals, can result in reduced milk yield and increased replacement cost (Pryce et al., 2000; Kadarmideen et al., 2003). Although there are several studies that have investigated the association between fertility and production traits, there are few studies (Beaudeau et al., 1994; Schneider et al., 2005; Perez-Cabal et al., 2006; Sewalem et al., 2006) in the literature that examined the association of reproduction traits with longevity.

Survival analysis using a Weibull proportional hazards model can offer a better fit to survival data due to its ability to properly account for censored and uncensored records. This would allow better survival estimates by accounting for differences in days of productive life between cows that survive for the same number of lactations. The methodology also accounts for the skewed distribution of survival. Time-dependent variables can be used for survival analysis to accurately model environmental effects (Ducrocq and Sölkner, 1998; Ducrocq, 2002). The objective of the present study was to analyze the relationship between various reproduction traits and functional longevity of Canadian Holstein, Ayrshire, and Jersey breeds.

\section{MATERIALS AND METHODS}

Data consisted of records of $1,702,857$ cows from 12,033 herds sired by 5,090 sires for Holstein, 67,470 cows in 684 herds from 1,496 sires for Ayrshires and 33,190 cows in 800 herds from 1,288 sires for Jersey. Data were obtained from lactation and reproduction records extracted for the February 2006 genetic evaluation of the Holstein, Jersey, and Ayrshire breeds that calved from 1998 to 2005 . Records with missing sire identification, incorrect calving dates, or age at first calving outside the 18 to 40 mo range were excluded from the analysis. Reproduction traits included calving traits and female fertility traits, and all cows were required to have at least one of these to be included in the analyses. Calving traits included traits such as calving ease with 4 classes (unassisted, easy pull, hard pull, and surgery), calf size with 3 classes (measured subjectively by farmers as small, medium, and large), and calf survival with 2 classes (dead or alive within $24 \mathrm{~h}$ after calving). Female fertility traits included traits such as number of services with 6 classes $(1,2,3,4,5$, and 6+), days from first service to conception with 6 classes (each class consisting of a 21-d interval), days from calving to first service with 5 classes (each class consisting of a 30-d interval), and days open with 6 classes (each class consisting of a 30-d interval). De-

Table 2. Percentage of first-parity records of calving ease by calf size (small, medium, and large) and sex in Holsteins ${ }^{1}$

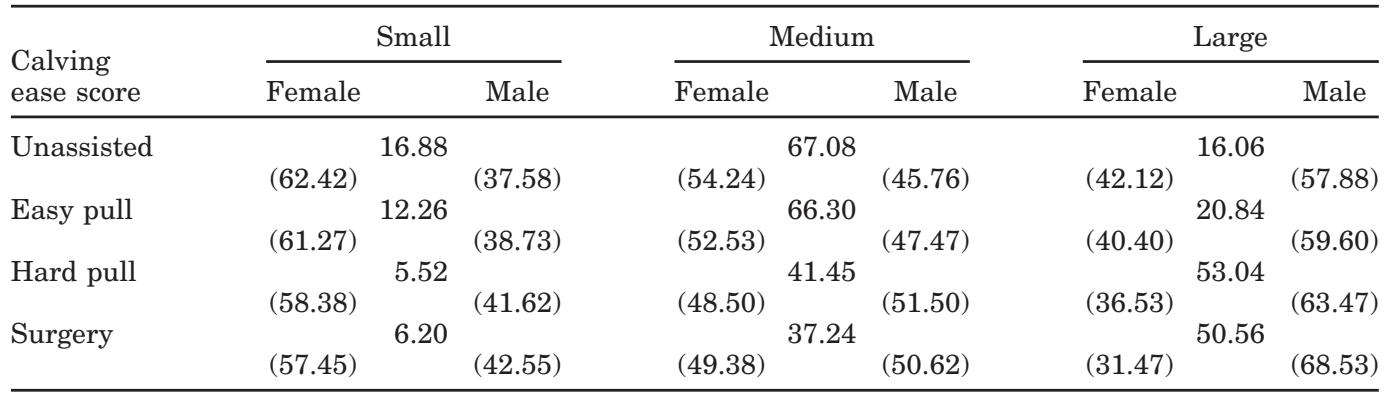

${ }^{1}$ Numbers in parentheses are female and male percentage of records, respectively, in each class of calving score. $\mathrm{CE}=$ calving ease, $\mathrm{CZ}=$ calf size, $\mathrm{CS}=$ calf survival. 
Table 3. Percentage of first parity records for calving traits in each classes of calving ease in Holsteins

\begin{tabular}{lrc}
\hline Item & \multicolumn{3}{c}{ Calf survival } \\
\hline Calving ease & Dead & Alive \\
Unassisted & 5.2 & 94.8 \\
Easy pull & 4.2 & 95.8 \\
Hard pull & 16.5 & 81.5 \\
Surgery & 28.8 & 71.2 \\
Calf size & & \\
Small & 5.9 & 94.2 \\
Medium & 4.4 & 95.6 \\
Large & 11.8 & 88.2 \\
\hline
\end{tabular}

tailed description and definition of reproductive traits can be found in Jamrozik et al. (2005). The distributions of records by class for each trait are presented in Tables $1,2,3$, and 4 .

Length of productive life was defined as time (days) from first calving to the next calving, death, or culling. Records of cows being sold for dairy purposes, exported, or leased to another herd or cows still in the herd were censored. A lifetime record was considered to be completed (uncensored) if the cow received a termination code, indicating that the cow was removed for any reason. The following model was used to analyze the impact of reproduction traits on survival:

$$
\lambda(t)=\lambda_{0, s}(t) \exp \left\{\mathbf{x}_{\boldsymbol{m}}^{\prime}(t) \beta+\mathbf{z}_{\boldsymbol{m}}^{\prime} \boldsymbol{u}\right\}
$$

where $\lambda(t)$ is the hazard of a cow (i.e., her probability of being culled at time $t$ given she is alive just before $t) ; \lambda_{0, \mathrm{~s}}(\mathrm{t})=\lambda \rho(\lambda \mathrm{t})^{\rho-1}$ is the Weibull baseline hazard function with scale parameter $\lambda$ and shape parameter $\rho$; and $\mathrm{t}$ is the time in days from 1 calving to the next calving or date of culling or censoring for each stratum (lactation numbers greater than 6 were set to 6 ); $\beta$ contains the possibly time-dependent covariates affecting the hazard with $\boldsymbol{x}_{\mathbf{m}}^{\prime}(t)$ being the corresponding design vectors; and $\mathbf{u}$ is a vector of random variables with associated incidence vector $\mathbf{z}_{\mathbf{m}}^{\prime}$. One baseline hazard function $\boldsymbol{\lambda}_{0, \boldsymbol{s}}(\boldsymbol{t})$ was defined for each lactation (subscript $\mathbf{0}$ designates a baseline hazard and subscript $\mathbf{s}$ relates stratum s). A detailed description of the model and survival analysis of longevity data in dairy cattle on a lactation basis was described by Ducrocq (2002) and Roxstrom et al. (2003).

The fixed covariates included in the model were as follows: time-dependent effect of stage of lactation in days ( $1=0$ to $80 ; 2=81$ to $235 ; 3=$ more than $235 \mathrm{~d}$ ); effect of year and season of calving (year of calving from 1985 to 2003; seasons of calving were January to March, April to June, July to September, and October to December); effect of season of production with the same definition as seasons of calving; effect of the annual change in herd size with 3 classes (decreasing $=$ for a decrease in herd size of $<-5 \%$; nearly unchanged $=$ no appreciable change $\geq-5 \%$ to $\leq 10 \%$; and increasing = an increase in herd size of $>10 \%$ ); effect of the type of milk recording supervision with 3 classes [unsupervised, supervised, and unknown (i.e., records that do not fulfill the minimum criteria set by the milk recording agency)]; effect of age at first calving in months; and effects of annual milk, fat, and protein yields. The latter effects were calculated as within herd-year-parity deviations with 3 classes for each as in Sewalem et al. (2005): low = cows producing more than $0.4 \mathrm{SD}$ below the herd-yearparity average; average $=$ cows producing between 0.4 SD below and 0.6 SD above the herd-year-parity average; and high = cows producing above $0.6 \mathrm{SD}$ of the herd-year-parity average. Each reproduction trait was evaluated separately and was included as a covariate in the model. The term length of productive life refers to functional longevity, which is corrected for production.

The random effects included were the effect of herdyear-season class, assumed to follow a log gamma distribution, and the genetic effect of the cow's sire, which was assumed to follow a multivariate normal distribution with mean zero and variance $\mathbf{A} \sigma^{2} \mathbf{s}$, where $\sigma^{2} \mathbf{s}$ is sire variance and $\mathbf{A}$ is the relationship matrix. Sire variances of 0.046, 0.039, and 0.040 for Holstein, Ayrshire, and Jersey, respectively, were used in the analyses (Sewalem et al., 2005).

Table 4. Percentage of records for female fertility traits ${ }^{1}$ in each class for Holstein (HO), Ayrshire (AY), and Jersey (JE)

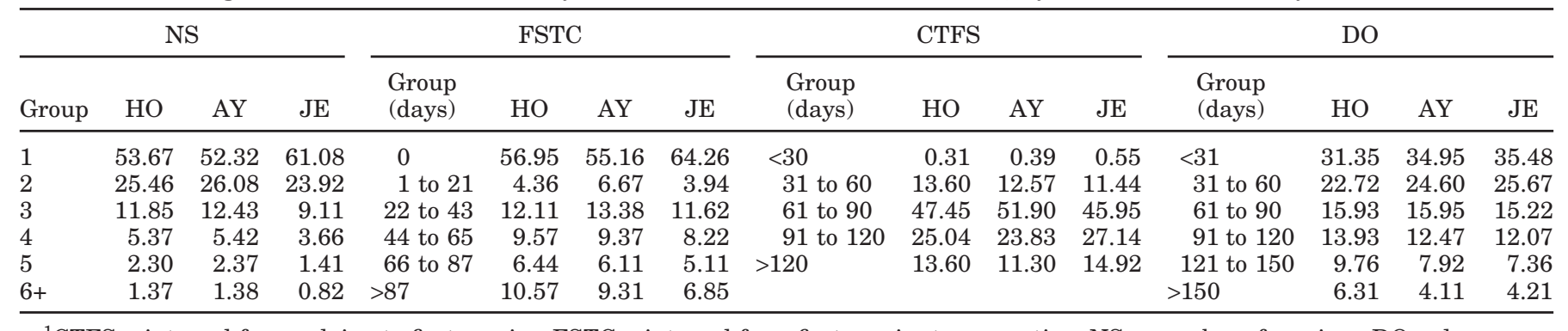

${ }^{1} \mathrm{CTFS}=$ interval from calving to first service, FSTC = interval from first service to conception, NS = number of services, DO = days open. 


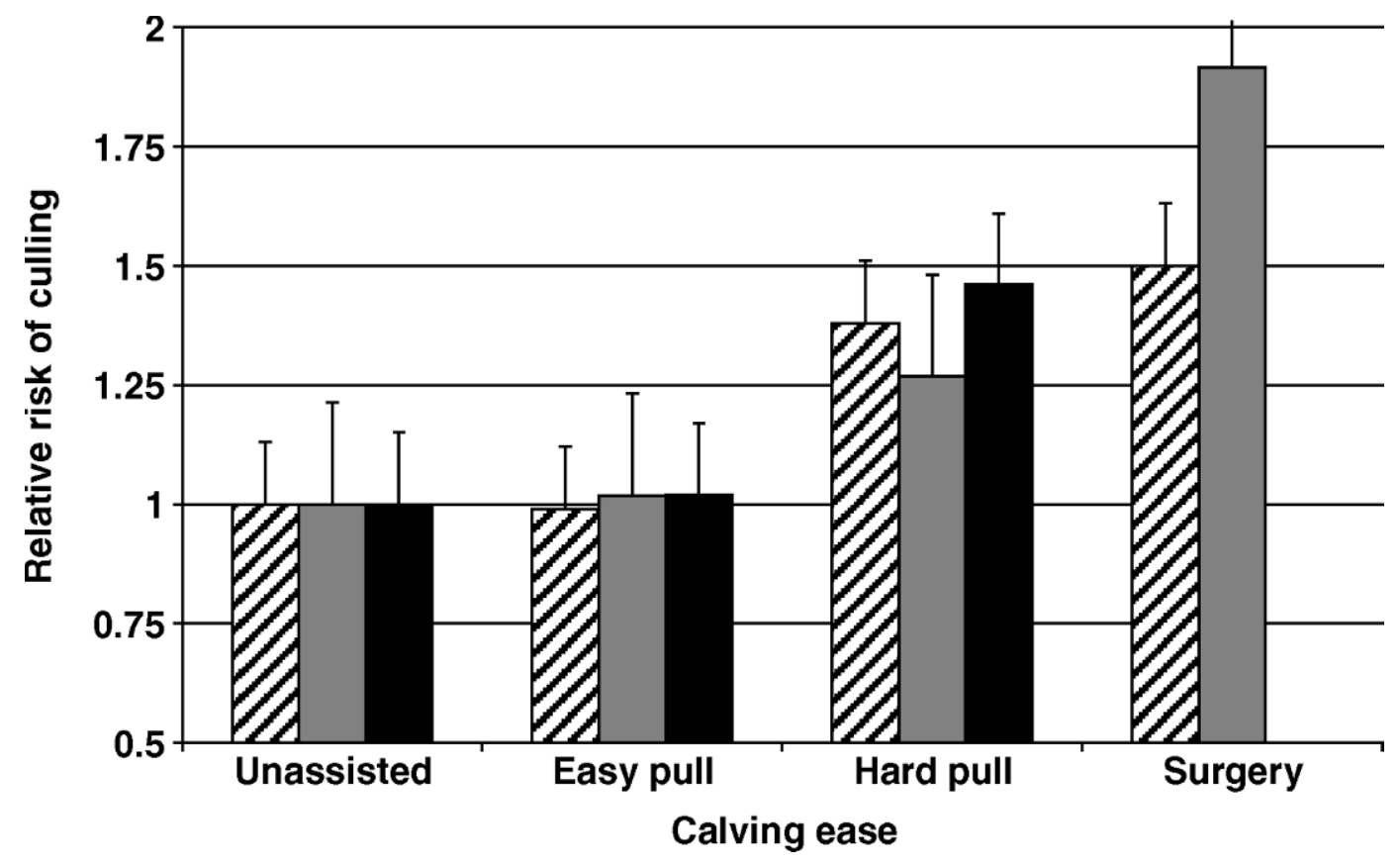

Figure 1. Relative risk of culling for calving ease (relative culling rate for unassisted was set to 1). Ayrshires (diagonal lines), Holsteins (gray shading), and Jerseys (black shading): minimum 25 uncensored failures per subclass. Bars on the graph indicate standard errors.

The analyses, using a Weibull proportional hazards model, were performed using the Survival Kit Version 5.1 (Ducrocq and Sölkner, 1998). The overall influence of reproductive traits on functional survival was assessed using the likelihood ratio test. Significance was determined by comparing the full model (with classes of reproduction traits) to the reduced model (without classes of reproduction traits). The analysis was done separately by breed.

\section{RESULTS AND DISCUSSION}

All reproduction traits had a highly statistically significant $(P<0.001)$ association with functional longevity in Holsteins, Ayrshires, and Jerseys. The results are expressed as relative culling risk, defined as the ratio of the estimated risk of being culled under the influence of certain environmental factors relative to the average risk (or reference risk). This was usually set to 1 for the average reproduction trait. Values greater than 1 indicate increased culling risk associated with that environmental factor. Culling risks lower than 1 indicate lower culling risks, following the approach by Larroque and Ducrocq (2001), Caraviello et al. (2003), and Schneider et al. (2003). For example, if the relative culling risk for a given class is 2 , a cow in that class has twice the risk of being culled compared with a cow in the reference class for that effect.

\section{Calving Ease}

Table 2 shows the proportion of records for calving ease score by calf size and sex of calf in Holsteins. In both unassisted and easy pull categories the medium calf size groups were a greater proportion compared with the small and large calf size groups. However, the proportion of medium size calves decreased in hard pull and surgery calving ease categories, whereas the proportion of large calf size group increased as calving difficulty increased. The female to male ratio within each calf size group was also different across the calving ease categories. In the large calf size group, the proportion of males was larger than females, and this proportion was greater for hard pull and surgery categories. On the other hand, the male ratio was lower than the female proportion in the small calf size group. In all calf size groups, the proportion of male calf size increased across the calving ease categories.

Figure 1 shows the relationship between calving ease and longevity in the 3 breeds. Cows calving with hard pull and surgery had a considerably increased relative risk of culling in all breeds compared with cows calving unassisted. For instance, Holsteins cows calving with hard pull and surgery were 1.27 and 1.92, respectively, times more likely to be culled compared with the reference class (cows calving unassisted). The corresponding figures for Ayrshires were 1.38 and 1.50. In Jerseys, 


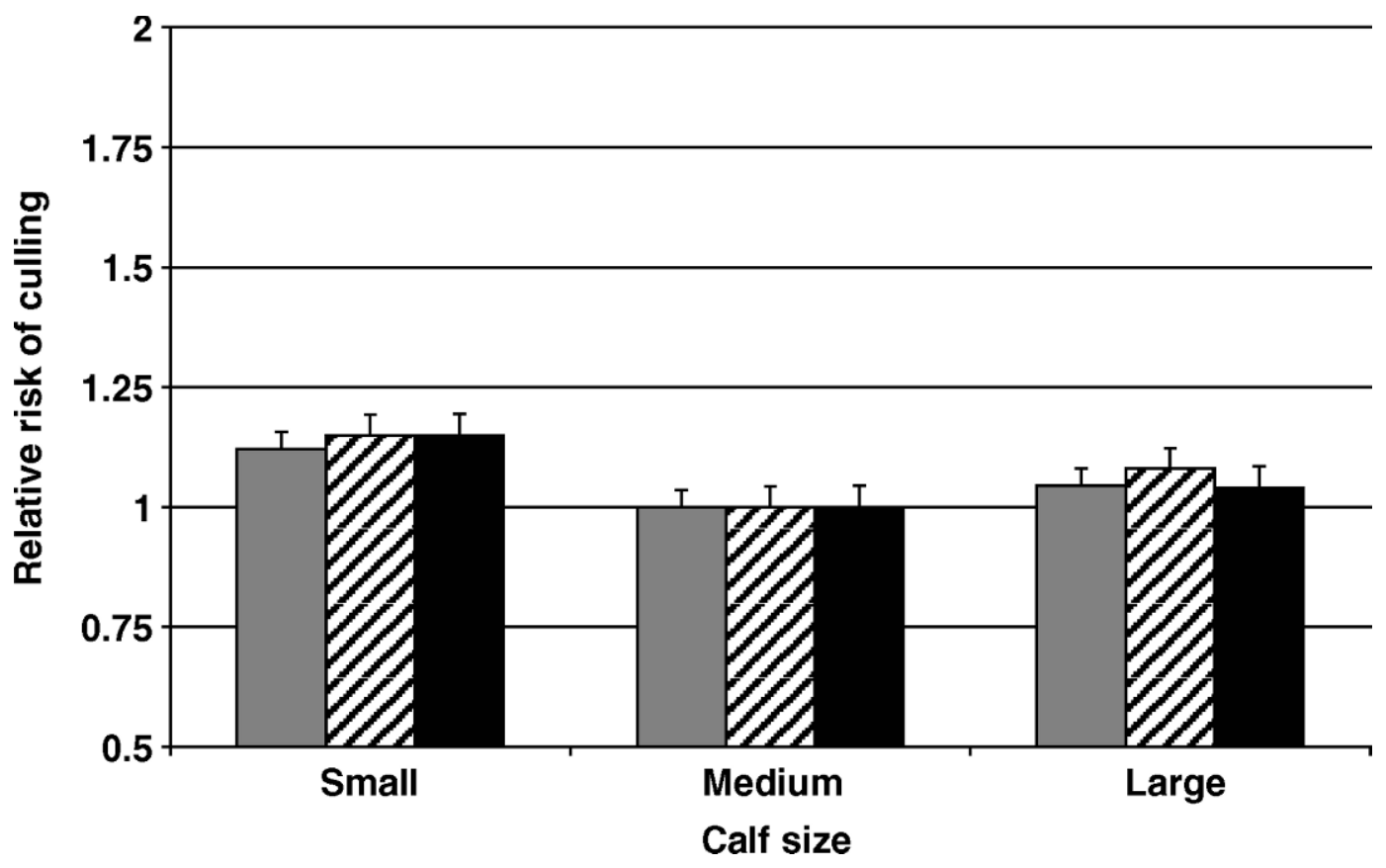

Figure 2. Relative risk of culling for calf size (relative culling rate for medium size was set to 1). Ayrshires (diagonal lines), Holsteins (gray shading), and Jerseys (black shading): minimum 25 uncensored failures per subclass. Bars on the graph indicate standard errors.

cows calving with hard pull were 1.46 times more likely to be culled compared with the reference group. Calving ease is an important economic trait because of its impact on calf and heifer mortality, labor and veterinary expenses at calving time, and subsequent rebreeding performance of cows. High incidence of dystocia reduces profitability in herds and reduces reproductive performance in the next reproductive cycle, and decreases milk yield (Dekkers, 1994). The problems caused by calving difficulty increase the culling rate in herds, substantially affecting longevity in dairy cows (Dematawewa and Berger, 1998; Sewalem et al., 2006). Lopez de Maturana et al. (2007) reported that calvings needing assistance or surgery increased culling risk by $10 \%$, when compared with unassisted calvings. As shown in Table 2, the proportion of large calf size increased across the 4 calving ease categories. Jamrozik et al. (2005) estimated a genetic correlation of 0.58 between calving difficulty and calf size in Canadian Holsteins.

\section{Calf Size}

With regard to calf size and longevity, there was a slight tendency of favoring cows with an intermediate calf size (Figure 2). For instance, in Holsteins, cows calving a small or large calf were 1.12 and 1.04 times more likely to be culled compared with the reference class (cows calving an intermediate calf). The corresponding figures for Jersey were 1.15 and 1.04 and for
Ayrshire were 1.15 and 1.08, respectively. Jamrozik et al. (2005) reported a genetic correlation of 0.50 between gestation length and calf size. This finding may suggest that the higher risk of cows calving a small calf may be due to shorter gestation length, which, in turn, may be associated with reproductive problems and other disease conditions.

\section{Calf Survival}

Table 3 shows the proportion of calf survival (dead or alive) for calving ease and calf size categories. The proportions of calf survival for unassisted, easy pull, hard pull, and surgery were $94.8,95.8,81.5$, and $71.2 \%$, respectively, indicating that the proportion of dead calves increased by more than 5 times from unassisted to surgery calving ease categories. The proportion of dead or alive calves was also different among the calf size groups. In the large calf size group, the proportion of dead calves was 11.8, whereas it was only $5.9 \%$ among small calf sizes. Cows with a dead calf had a greater risk of being culled. According to the average across all 3 breeds, the relative risk of culling for cows having a stillborn calf was $33 \%$ greater than for cows calving normally. Calf survival is a complex trait influenced by several environmental and genetic factors such as parity, sex of calf, gestation length, and calving difficulty. Various reports indicated that stillbirths were associated with increased risk of developing mas- 


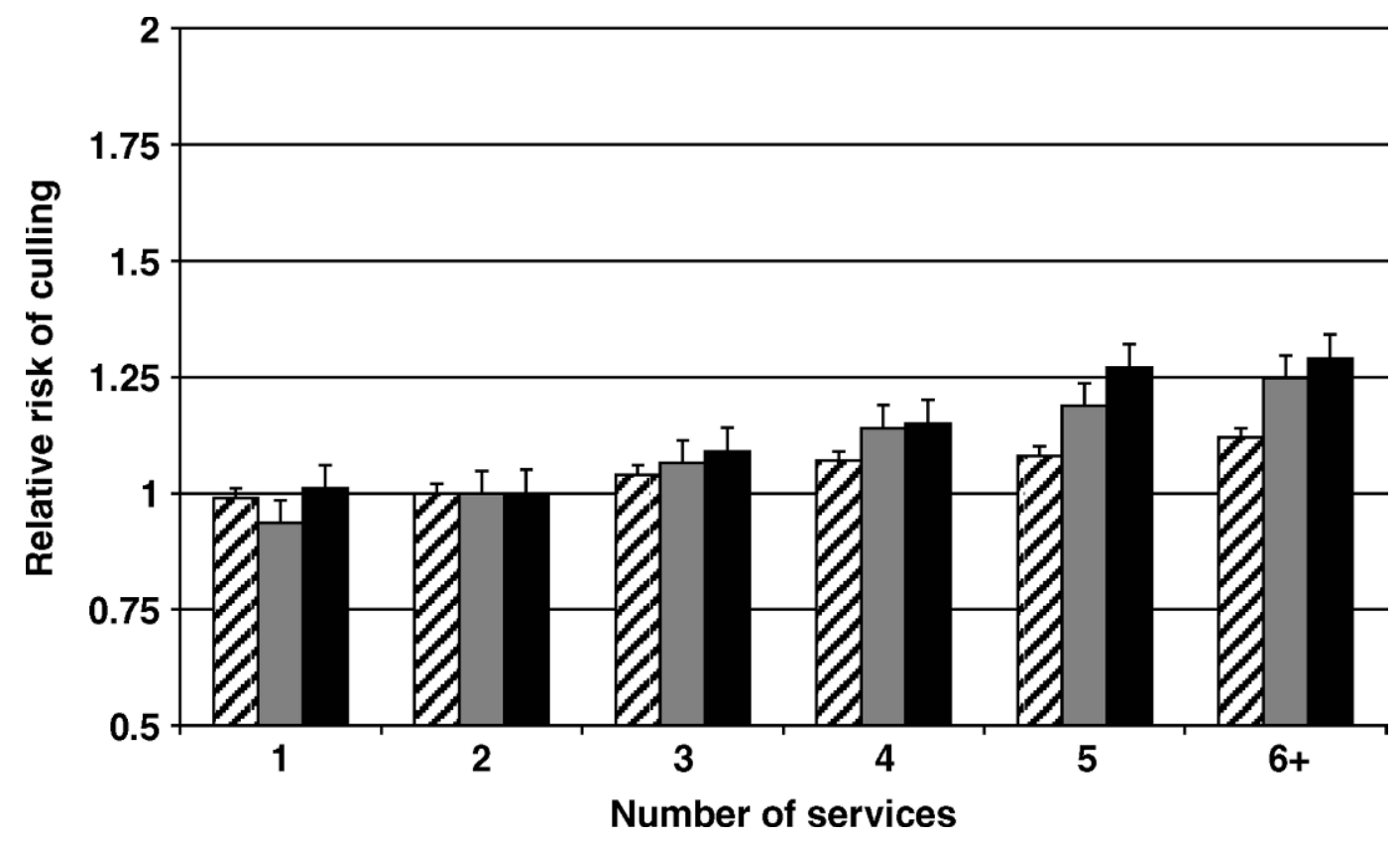

Figure 3. Relative risk of culling for number of services (relative culling rate for number of services 2 was set to 1). Ayrshires (diagonal lines), Holsteins (gray shading), and Jerseys (black shading): minimum 25 uncensored failures per subclass. Bars on the graph indicate standard errors.

titis, retained placenta, and decreased rate of conception compared with the rest of population (Emanuelson et al., 1993). Mangurkar et al. (1984) reported that calvings associated with dead calves led to higher culling rates due to lower milk production and impaired reproductive performance when compared with live calvings. Bicalho et al. (2007) also reported that cows that had stillbirths had significantly increased risk of being culled and increased days open by $88 \mathrm{~d}$ compared with cows that had live calves.

\section{Number of Services Per Conception}

Figure 3 shows the relative risk of culling for number of services required per conception in the 3 breeds. As the number of services per conception increased, the relative risk of culling increased in all breeds. Cows that required a fourth and fifth service per conception were more likely to be culled compared with cows that required 2 services per conception (breed average). For instance, Holstein cows requiring 4 and 5 services were 1.14 and 1.19, respectively, more likely to be culled compared with the reference group. The corresponding figures for Ayrshires were 1.07 and 1.08 and for Jerseys were 1.27 and 1.29. Furthermore, cows with more than 6 services had a risk of being culled 1.25 times more than that of cows in the reference class in Holsteins, 1.12 times in Ayrshires, and 1.29 times in Jerseys. On the other hand, cows that required a single service for conception were found to have no apparent difference in longevity from cows with the reference group.

\section{Days from Calving to First Service}

Figure 4 shows the relationship between the interval from calving to first service and functional longevity. Cows that were first inseminated $90 \mathrm{~d}$ or more after calving were at a greater risk of being culled compared with cows in the reference class (61 to $90 \mathrm{~d}$ ). In Holsteins, cows first inseminated after $120 \mathrm{~d}$ from calving were 1.19 times more likely to be culled compared with the reference group. The corresponding figures were smaller for Ayrshire (1.10) and for Jersey (1.06).

\section{Days from First Service to Conception}

Figure 5 shows the relationship between interval from first service to conception and functional longevity. After the first service, as the number of days increased, the relative risk of culling of cows also increased linearly in all 3 breeds. Holstein cows that conceived within 44 to $65 \mathrm{~d}$ and 66 to $87 \mathrm{~d}$ after the first service were 1.04 and 1.10 times, respectively, more likely to be culled compared with the reference group. The corresponding figures for Ayrshires were 1.07 and 1.11 and for Jerseys were 1.04 and 1.14. Moreover, cows conceiving at the first service $(0 \mathrm{~d}$ from first service to conception) were not apparently different in terms of 


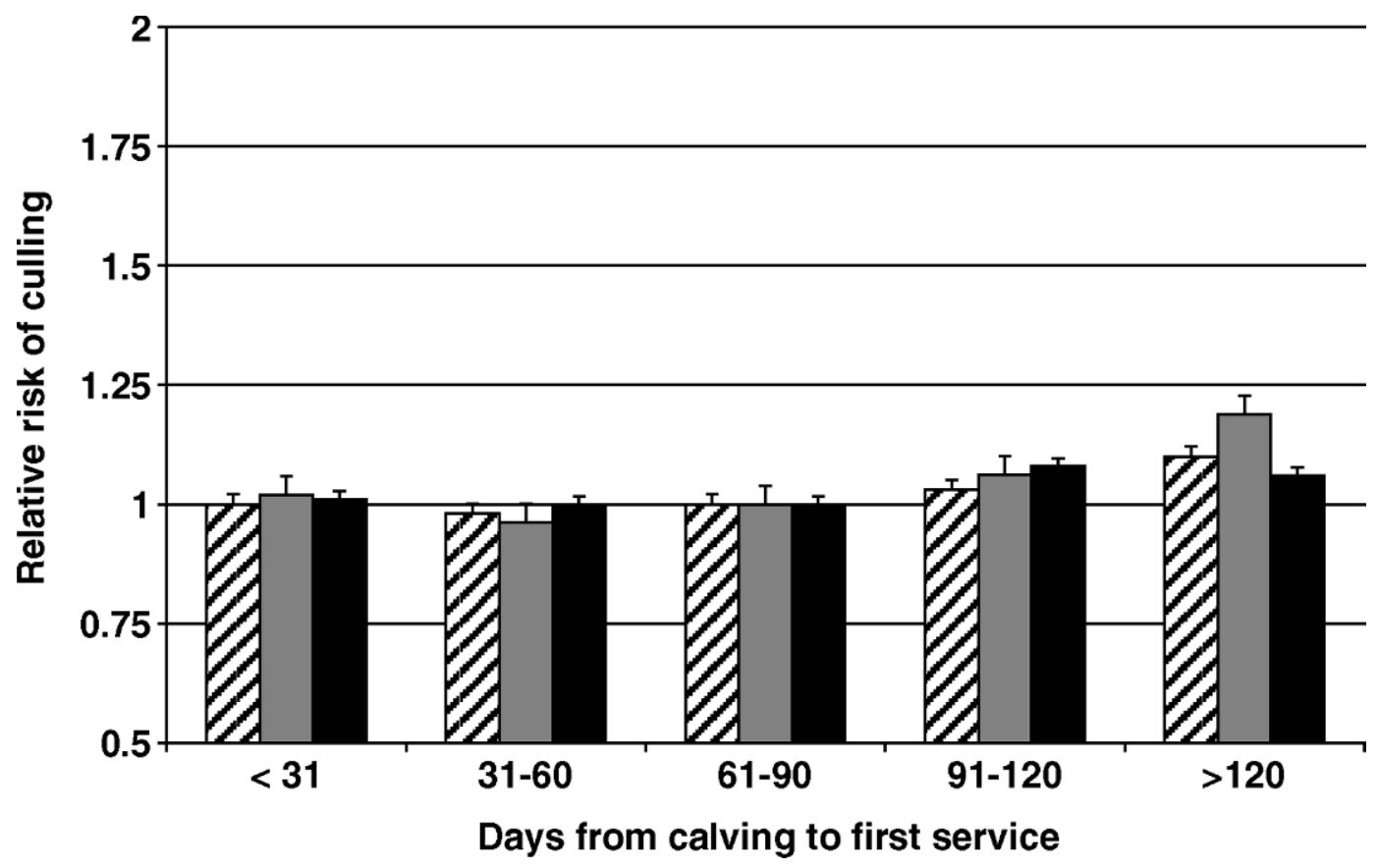

Figure 4. Relative risk of culling for calving to first service (relative culling rate for d 61 to 90 was set to 1). Ayrshires (diagonal lines), Holsteins (gray shading), and Jerseys (black shading): minimum 25 uncensored failures per subclass. Bars on the graph indicate standard errors.

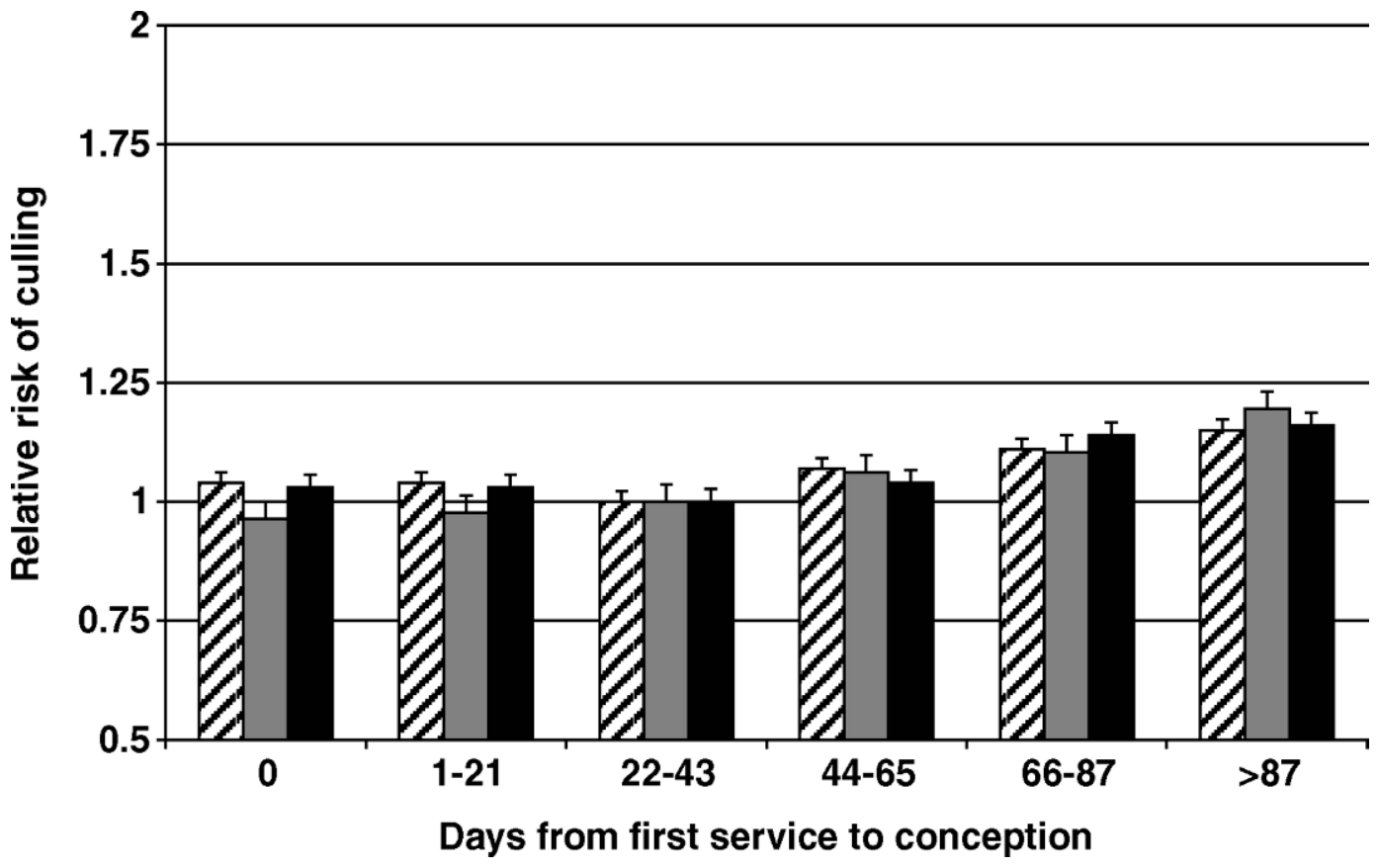

Figure 5. Relative risk of culling for first service to conception (relative culling rate for d 22 to 43 was set to 1). Ayrshires (diagonal lines), Holsteins (gray shading), and Jerseys (black shading): minimum 25 uncensored failures per subclass. Bars on the graph indicate standard errors. 


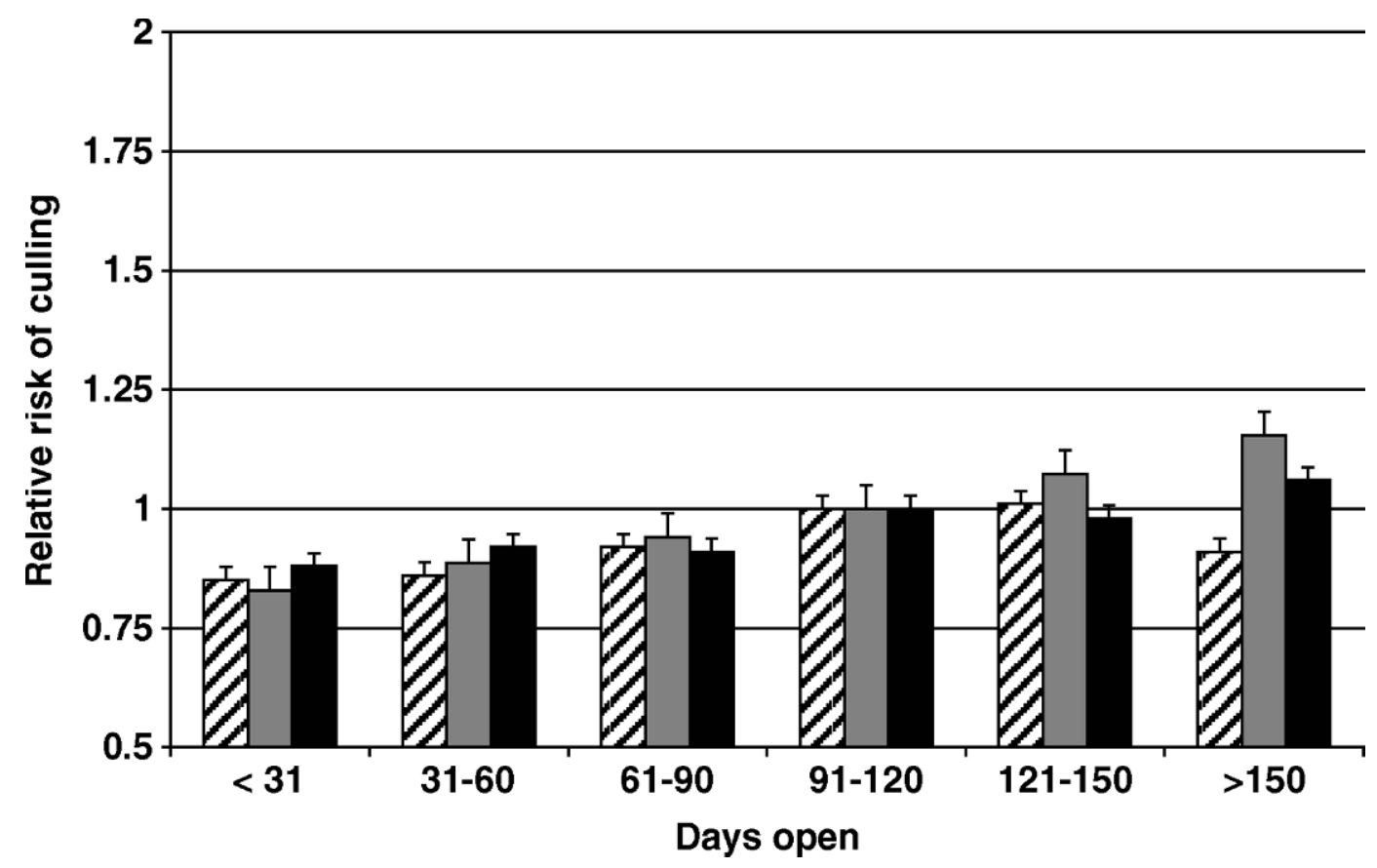

Figure 6. Relative risk of culling for days open (relative culling rate for d 91 to 120 was set to 1). Ayrshires (diagonal lines), Holsteins (gray shading), and Jerseys (black shading): minimum 25 uncensored failures per subclass. Bars on the graph indicate standard errors.

the relative risk of culling compared with reference group.

\section{Days Open}

Figure 6 shows the relationship between the relative risk of culling and days open in the 3 breeds. There was a slight linear relationship between days open and relative culling rate. In Holsteins, cows open more than $150 \mathrm{~d}$ were 1.15 times more likely to be culled compared with cows to the reference group (91 to $120 \mathrm{~d}$ ). In Jersey and Ayrshire breeds, there was no significant difference in terms of relative risk of culling when the days open was longer than the breed average (91 to $120 \mathrm{~d}$ ). On the other hand, in all breeds, cows with fewer days open than the breed average had longer survival than did cows with the breed average days open. Beaudeau et al. (1994) also reported that cows with longer days open had increased risk of culling.

Poor reproduction increases culling rates and replacement costs. Therefore, the ability of the cow to conceive and maintain pregnancy is among the most important components of dairy herd management for maintaining high production and longevity of dairy cows. Although reproduction traits are largely influenced by nongenetic factors, genetic variability is present, so adoption of an appropriate recording system and incorporation of these traits in the overall breeding objective may result in marginal improvements in reproduction and resistance to involuntary culling.

Results from this study are from a model that included a sire genetic effect. Larroque and Ducrocq (2001) argued that inclusion of the genetic effect in the model would bias the estimate of the effect of a trait's phenotypic effect on culling risks. However, similar to analyses of other traits such as production, correcting known causes of effects for a trait is a worthwhile consideration, and inclusion of the genetic effects in the model eliminates any sort of bias that might arise in the process of culling. Also, Schneider et al. (2003) and Sewalem et al. (2004) found no differences between phenotypic and genetic analysis of type traits and their impact on functional survival of cows. In this study, a phenotypic analysis of each trait (excluding the sire effect in the model) was also analyzed, and results were compared with the present study (not shown). There were no changes in the significance tests. The absence of clear differences between the 2 models (excluding and including the genetic effect in the model) might have been due to a dominance of the phenotypic influence on survival.

\section{CONCLUSIONS}

Survival analysis was used to investigate the relationship between reproduction traits and functional 
longevity in Canadian dairy cattle. The study showed a significant association between reproduction traits and functional longevity in Canadian dairy breeds. Cows with poor fertility were at higher risk of being culled compared with the reference class. Moreover, cows calving with the help of surgery, heifers calving dead calves and large calves had shorter longevity compared with the reference class.

\section{ACKNOWLEDGMENTS}

Appreciation is extended to Vincent Ducrocq (Station de Génétique Quantitative et Appliquée-INRA, 78352 Jouy-en-Josas, France) for providing the Survival Kit V5.1 software.

\section{REFERENCES}

Allaire, F. R., and J. P. Gibson. 1992. Genetic value of herd life adjusted for milk production. J. Dairy Sci. 75:1349-1356.

Beaudeau, F., V. Ducrocq, C. Fourchon, and H. Seegers. 1994. Effect of disease on productive life of French Holstein dairy cows assessed by survival analysis. J. Dairy Sci. 78:103-117.

Bicalho, R. C., K. N. Galva, S. H. Cheong, R. O. Gilbert, L. D. Warnick, and C. L. Guard. 2007. Effect of stillbirths on dam survival and reproduction performance in Holstein dairy cows. J. Dairy Sci. 90:2797-2803.

Caraviello, D. Z., K. A. Weigel, and D. Gianola. 2003. Analysis of the relationship between type traits, inbreeding, and functional survival in Jersey cattle using a Weibull proportional hazards model. J. Dairy Sci. 86:2984-2989.

Dekkers, J. C. M. 1994. Optimal breeding strategies for calving ease. J. Dairy Sci. 77:3441-3453.

Dematawewa, C. M. B., and P. J. Berger. 1998. Genetic and phenotypic parameters for 305-day yield, fertility, and survival in Holsteins. J. Dairy Sci. 81:2700-2709.

Ducrocq, V. 2002. A piecewise Weibull mixed model for the analysis of length of productive life of dairy cows. Proc. 7th World Congr. Genet. Appl. Livest. Prod., Montpellier, France. Communication No. 20-04.

Ducrocq, V., and J. Sölkner. 1998. The Survival Kit version (V5.1) a Fortran package for the analysis of survival data. Proc. 6th World Congr. Genet. Appl. Livest. Prod., Armidale, Australia. 27:447448.

Emanuelson, U., A. P. Oltenacu, and Y. T. Grohn. 1993. Nonlinear mixed model analyses of five production disorders of dairy cattle. J. Dairy Sci. 76:2765-2772.

Jamrozik, J., J. Fatehi, G. J. Kistemaker, and L. R. Schaeffer. 2005. Estimates of genetic parameters for Canadian Holstein female reproduction traits. J. Dairy Sci. 88:2199-2208.

Kadarmideen, H. N., R. Thompson, M. P. Coffey, and M. A. Kossaibati. 2003. Genetic parameters and evaluations from single- and multi- ple trait analysis of dairy cow fertility and milk production. Livest. Prod. Sci. 81:183-195.

Larroque, H., and V. Ducrocq. 2001. Relationship between type and longevity in the Holstein breed. Genet. Sel. Evol. 33:39-59.

Leitch, H. W. 1994. Comparison of international selection indices for dairy cattle breeding. Interbull Bulletin no. 10.

Lopez de Maturana, E. L., E. Ugarte, and O. Gonzalez-Recio. 2007. Impact of calving ease on functional longevity and herd amortization costs in Basque Holsteins using survival analysis. J. Dairy Sci. 90:4451-4457.

Mangurkar, B. R., J. F. Hayes, and J. E. Moxley. 1984. Effects of calving ease-calf survival on production and reproduction in Holsteins. J. Dairy Sci. 67:1496-1509.

Miglior, F., B. L. Muir, and B. J. Van Doormaal. 2005. Selection Indices in Holstein Cattle of Various Countries. J. Dairy Sci. 88:1255-1263.

Miglior, F., A. Sewalem, G. J. Kistemaker, and B. J. Van Doormaal. 2007. Daughter Fertility (DF), Daughter Calving Ability (DCA), and Calving Ability (CA). Indexes by Breed; Report to the Genetic Evaluation Board, October 2007, Guelph, ON, Candada. http:// www.cdn.ca/Articles/GEBOCT2007/Reproductive\%20Indices\% 20-\%20GEB\%2010-2007\%20OUT.pdf

Perez-Cabal, M. A., C. García, O. Gonzalez-Recio, and R. Alenda. 2006. Genetic and phenotypic relationships among locomotion type traits, profit, production, longevity, and fertility in Spanish dairy cows. J. Dairy Sci. 89:1776-1783.

Pryce, J. E., M. P. Coffey, and S. Brotherstone. 2000. The genetic relationship between calving interval, body condition score and linear type and management traits in registered Holsteins. J. Dairy Sci. 83:2664-2671.

Roxstrom, A., V. Ducrocq, and E. Strandberg. 2003. Survival analysis of longevity in dairy cattle on a lactation basis. Genet. Sel. Evol. 35:305-318

Schneider, M., P. del, J. W. Durr, R. I. Cue, and H. G. Monardes. 2003. Impact of type traits on functional herd life of Quebec Holsteins assessed by survival analysis. J. Dairy Sci. 86:40834089.

Schneider, M. del P., E. Strandberg, V. Ducrocq, and A. Roth. 2005. Survival analysis applied to genetic evaluation for female fertility in dairy cattle. J. Dairy Sci. 88:2253-2259.

Sewalem, A., G. J. Kistemaker, V. Ducrocq, and B. J. Van Doormaal. 2005. Genetic analysis of herd life in Canadian dairy cattle on a lactation basis using a Weibull proportional hazards model. J. Dairy Sci. 88:368-375.

Sewalem, A., G. J. Kistemaker, F. Miglior, and B. J. Van Doormaal. 2004. Analysis of the relationship between type traits and functional survival in Canadian Holsteins using a Weibull proportional hazards model. J. Dairy Sci. 87:3938-3846.

Sewalem, A., G. J. Kistemaker, F. Miglior, and B. J. Van Doormaal. 2006. Analysis of the relationship between fertility traits and functional longevity in Canadian Holstein using a Weibull proportional hazards model. 8th World Congr. Genet. Appl. Livest. Prod., Belo Horizonte, MG, Brazil.

VanRaden, P. M., and G. R. Wiggans. 1995. Productive life evaluations: Calculation, accuracy and economic value. J. Dairy Sci. 78:631-638. 